\title{
Update on Cryptosporidium spp.: highlights from the Seventh International Giardia and Cryptosporidium Conference
}

Giovanni Widmer ${ }^{1}$, David Carmena ${ }^{2}$, Martin Kváč ${ }^{3,4}$, Rachel M. Chalmers ${ }^{5,6}$, Jessica C. Kissinger ${ }^{7}$ Lihua Xiao $^{8}$, Adam Sateriale 9 , Boris Striepen ${ }^{9}$, Fabrice Laurent ${ }^{10}$, Sonia Lacroix-Lamandé ${ }^{10}$, Gilles Gargala ${ }^{1,12}$, and Loïc Favennec ${ }^{11,12 . *}$

${ }^{1}$ Department of Infectious Disease \& Global Health, Cummings School of Veterinary Medicine at Tufts University, North Grafton, 01536 MA, USA

2 Spanish National Centre for Microbiology, 28220 Majadahonda, Spain

${ }^{3}$ Institute of Parasitology, Biology Centre CAS, 37005 České Budějovice, Czech Republic

${ }^{4}$ Faculty of Agriculture, University of South Bohemia in České Budějovice, 37005 České Budějovice, Czech Republic

${ }^{5}$ Cryptosporidium Reference Unit, Public Health Wales, SA2 8QA Swansea, UK

${ }^{6}$ Swansea Medical School, Swansea University, SA2 8PP Swansea, UK

7 Center for Tropical and Emerging Global Diseases, Institute of Bioinformatics and Department of Genetics, University of Georgia, Athens, 30602 GA, USA

${ }^{8}$ College of Veterinary Medicine, South China Agricultural University, Guangzhou, 510642 Guangdong, PR China

9 Department of Pathobiology, School of Veterinary Medicine, University of Pennsylvania, 380 South University Avenue, Philadelphia, 19104 PA, USA

${ }^{10}$ INRAE, Université François Rabelais de Tours, Centre Val de Loire, ISP, Laboratoire Apicomplexes et Immunité Mucosale, 37380 Nouzilly, France

${ }^{11}$ French National Cryptosporidiosis Reference Center, Rouen University Hospital, 1 Rue de Germont, 76031 Rouen Cedex, France

12 EA 7510, UFR Santé, University of Rouen Normandy, Normandy University, 22 Bd. Gambetta, 76183 Rouen Cedex, France

Received 20 February 2020, Accepted 2 March 2020, Published online 13 March 2020

\begin{abstract}
While cryptosporidiosis is recognized as being among the most common causes of human parasitic diarrhea in the world, there is currently limited knowledge on Cryptosporidium infection mechanisms, incomplete codification of diagnostic methods, and a need for additional therapeutic options. In response, the Seventh International Giardia and Cryptosporidium Conference (IGCC 2019) was hosted from 23 to 26 June 2019, at the Rouen Normandy University, France. This trusted event brought together an international delegation of researchers to synthesize recent advances and identify key research questions and knowledge gaps. The program of the interdisciplinary conference included all aspects of host-parasite relationships from basic research to applications to human and veterinary medicine, and environmental issues associated with waterborne parasites and their epidemiological consequences. In relation to Cryptosporidium and cryptosporidiosis, the primary research areas for which novel findings and the most impressive communications were presented and discussed included: Cryptosporidium in environmental waters, seafood, and fresh produce; Animal epidemiology; Human cryptosporidiosis and epidemiology; Genomes and genomic evolution encompassing: Comparative genomics of Cryptosporidium spp., Genomic insights into biology, Acquiring and utilizing genome sequences, Genetic manipulation; Host-parasite interaction (immunology, microbiome); and Diagnosis and treatment. High quality presentations discussed at the conference reflected decisive progress and identified new opportunities that will engage investigators and funding agencies to spur future research in a "one health" approach to improve basic knowledge and the clinical and public health management of zoonotic cryptosporidiosis.
\end{abstract}

Key words: Cryptosporidium, Cryptosporidiosis, Epidemiology, Genomics.

Résumé - Mise à jour sur Cryptosporidium spp.: Faits saillants de la Septième Conférence Internationale sur Giardia et Cryptosporidium. Bien que la cryptosporidiose soit reconnue comme l'une des premières causes de diarrhée parasitaire humaine dans le monde, la connaissance des mécanismes de l'infection par Cryptosporidium est limitée, la codification des méthodes diagnostiques est incomplète et des options thérapeutiques supplémentaires sont requises. En réponse à cette situation, la Septième Conférence Internationale sur Giardia and Cryptosporidium (IGCC 2019) s'est tenue du 23 au 26 juin 2019, à l'Université de Rouen-Normandie, France. Cet événement renommé a rassemblé une délégation internationale de chercheurs pour faire la synthèse des avancées récentes et identifier les principaux thèmes

*Corresponding author: Ioic.favennec@univ-rouen.fr

This is an Open Access article distributed under the terms of the Creative Commons Attribution License (https://creativecommons.org/licenses/by/4.0), which permits unrestricted use, distribution, and reproduction in any medium, provided the original work is properly cited. 
de recherche et les lacunes dans les connaissances. Le programme de cette conférence interdisciplinaire comprenait tous les aspects des relations hôte-parasite, de la recherche fondamentale aux applications à la médecine humaine et vétérinaire, ainsi que les questions environnementales liées aux parasites d'origine hydrique et leurs conséquences épidémiologiques. En ce qui concerne Cryptosporidium et la cryptosporidiose, les principaux domaines de recherche pour lesquels de nouvelles découvertes et les communications les plus impressionnantes ont été présentées et discutées comprenaient : Cryptosporidium dans les eaux environnementales, les fruits de mer et les produits frais ; Épidémiologie animale ; Cryptosporidiose et épidémiologie humaine ; Génomes et évolution génomique englobant : Génomique comparative des Cryptosporidium spp., Perspectives génomiques en biologie, Acquisition et utilisation des séquences du génome, Manipulation génétique ; Interaction hôte-parasite (immunologie, microbiome) ; Diagnostic et traitement. Les présentations de grande qualité discutées à la conférence ont fait état de progrès décisifs et ont permis de cerner de nouvelles possibilités qui inciteront les chercheurs et les organismes de financement à stimuler la recherche future dans une approche " une seule santé » afin d'améliorer les connaissances de base et la gestion clinique et de santé publique de la cryptosporidiose zoonotique.

\section{Introduction}

The Seventh International Giardia and Cryptosporidium Conference (IGCC) was held in Rouen, France, from 23 to 26 June 2019. The conference, which covered various research areas on Cryptosporidium and cryptosporidiosis, including epidemiology, genomics and genome evolution, genetic manipulation, host parasite interaction, and diagnosis and treatment, was attended by 237 researchers from more than 100 research teams from 34 countries. We would like to highlight here the most impressive communications and novel findings presented at the IGCC-7.

\section{Cryptosporidium in environmental waters, seafood, and fresh produce}

Cryptosporidium spp. are largely recognized as common causes of water- and food-borne outbreaks of diarrheal illness globally $[11,30]$. Waterborne transmission is a major route in the epidemiology of the parasite and is thus a serious public health concern. As a reflection of the interest in the transmission of cryptosporidiosis, a significant number of studies presented at IGCC-7 focused on the detection and quantification of Cryptosporidium oocysts in surface (Cho et al., p. 56 in [29]; Hatalová et al., p. 58 in [29]; Wells et al., p. 130; p. 164 in [29]; Cirkovic et al., p. 132 in [29]), recreational (Chalmers et al., p. 185 in [29]), and waste water matrices (Zahedi et al., p. 126 in [29]; Cervero-Aragó et al., p. 129 in [29]). Most of these surveys were conducted using different methodological approaches (concentration, purification, and identification), in spite of the existence of standard methods (e.g., ISO 15553, USEPA 1623, and 1693). More effort should be devoted to understanding the factors (e.g., cost, availability, feasibility) behind the motivation not to use procedures approved for routine or regulatory monitoring.

Livestock (mainly cattle) and wildlife (deer and migrating geese) were demonstrated as relevant contributors to zoonotic Cryptosporidium oocysts in source water catchments intended for human consumption (Wells et al., p. 130; p. 164 in [29]), but wildlife control measures may be difficult to implement due to legal and conservation issues.

Importantly, new technologies such as ceramic candle filters (Abeledo-Lameiro et al., p. 142 in [29]) and alternative sampling strategies including aquatic biofilms (Jellison et al., p. 122 in [29]; Ortega et al., p. 124 in [29]), adapted methods for use in swimming pool waters (Chalmers et al., p. 185 in [29]), qPCR assays applied to partially purified oocysts on microscope slides (Elwin et al., p. 133, in [29]) and next generation sequencing (NGS) approaches (Zahedi et al., p. 126 in [29]) have been developed to sample and detect the parasite in different water matrices.

Large-scale foodborne outbreaks of cryptosporidiosis have been documented globally in recent years [30]. Therefore, increasing attention is being paid to the detection of Cryptosporidium oocysts in fresh produce including lettuce, parsley, coriander, fruits, and sprout seeds (Berrouch et al., p. 135 in [29]; Bartošová et al., p. 136 in [29]). Standard methods for food are limited to leafy greens and berry fruits (ISO 18744; BMA19A). It was evident in these surveys that a variety of methods were used, making it difficult to directly compare results among different research groups. The use of qPCR increased detection sensitivity, but a lack of genotyping and sub-genotyping data makes it impossible to fully evaluate the public health relevance of these findings. Edible filtrating molluscs, including oysters, have been proposed as potential sources of human cryptosporidiosis (Santos et al., p. 57 in [29]), although no recognized outbreaks have been documented so far [21]. Interestingly, small crustaceans of the genus Artemia have been successfully used as a bio-indicator for the presence of zoonotic Cryptosporidium oocysts in water reservoirs (Hatelová et al., p. 58 in [29]).

\section{Animal epidemiology}

Molecular tools are increasingly being used for genotyping and subtyping of Cryptosporidium spp. originating from farm, domestic and wild animals, and for monitoring the sources of infections and transmission routes. Although Sanger sequencing technology still prevails, the use of NGS has increased in recent years. NGS is advantageous for detecting mixed infections, as these technologies are able to identify more subtypes infecting the same host than those revealed by Sanger sequencing (Santín et al., p. 165 in [29]). It is now also possible to amplify DNA from individually purified Cryptosporidium oocysts, a method that has been used to ascertain the genetic population of the parasite at the herd/farm level or even within individuals; however, this method is not yet suitable for routine use (Gharieb et al., p. 166 in [29]). 
A series of studies has shown that livestock such as cattle, sheep, and goats remain the main zoonotic source of $C$. parvum infections in humans (Santín et al., p. 165 in [29]; Gharieb et al., p. 166 in [29]; Ongerth et al., p. 167 in [29]; Razakandrainibe et al., p. 168; p. 175 in [29]; Mammeri et al., p. 170 in [29]; Sahraoui et al., p. 171 in [29]; Bartley et al., p. 172 in [29]; Tesama et al., p. 178 in [29]). Subtyping of the $60 \mathrm{kDa}$ glycoprotein (gp60) locus revealed that the majority of $C$. parvum infections in these livestock worldwide were caused by the IIa and IId subtypes (Mammeri et al., p. 170 in [29]; Sahraoui et al., p. 171 in [29]; Mravcová et al., p. 180 in [29]; Razakandrainibe et al., p. 175 in [29]). Following these studies, reports from the UK and Australia showed that adult cattle had more $C$. parvum genotype diversity than calves, and that $C$. parvum subtypes remain stable for long periods on the same farm (Shaw et al., p. 162 in [29]; Ongerth et al., p. 167 in [29]). The results presented at IGCC-7 also showed that adult cows do not represent the main source of Cryptosporidium infections for calves, as they are mostly infected from other calves (Shaw et al., p. 162 in [29]).

Although $C$. parvum subtype IIa, which is most prevalent in livestock, has been detected as a common pathogen in horses (Uiterwijk et al., p. 163 in [29]), wild ponies (Couso-Pérez et al., p. 71 in [29]), deer (Teixeira et al., p. 72 in [29]), and non-human primates (Wortea Hailu et al., p. 182 in [29]), all reports indicate that farm and wild mammals and birds are mostly parasitized by host-specific Cryptosporidium spp. In addition to the already known Cryptosporidium spp. in domestic and wild vertebrates - $C$. suis in pigs (Cervone et al., p. 174 in [29]), Cryptosporidium rat genotypes I and IV in rats (Kváč et al., p. 67 in [29]), C. muris and C. tyzzeri in mice (Kváč et al., p. 68 in [29]), C. xiaoi in sheep (Krumkamp et al., p. 111 in [29]), C. bovis and C. ryanae in cattle (Krumkamp et al., p. 111 in [29]), and Cryptosporidium molnari-like in fish (Gantois et al., p. 74 in [29]), novel genotypes have recently been reported: (i) a great tit genotype in great tit (Holubová et al., p. 67 in [29]); (ii) a swallow genotype in swallow (Holubová et al., p. 68 in [29]); and (iii) potentially novel genotypes (confirmation still pending) in trout (CousoPérez et al., p. 71 in [29]). These results are confirmation of the major trend of the last 10 years: there is still much to discover about the genus Cryptosporidium.

With the widespread use of molecular tools, C. parvum, the species most often associated with infections from water, has been increasingly detected in aquatic vertebrates. Studies from Poland, France, and Spain showed that turtles and fish can be passive carriers of C. parvum (Kaupke et al., p. 66 in [29]; Couso-Pérez et al., p. 71 in [29]; Gantois et al., p. 74 in [29]). Synanthropic rodents have also been reported as potential sources of $C$. parvum and $C$. hominis infections in human populations (Kváč et al., p. 69 in [29]). Conversely, a number of studies have shown Cryptosporidium transmission in the opposite direction. A study from Spanish zoos indicated the possible transmission of $C$. hominis and C. parvum from human (keeper) to non-human primates (Köster et al., p. 71 in [29]). Interestingly, various reports have described an increased frequency of detected cases of anthropogenic $C$. hominis in cattle (Krumkamp et al., p. 111 in [29]; Zahedi et al., p. 126 in [29]; Razakandrainibe et al., p. 175 in [29]) and kangaroos (Zahedi et al., p. 126 in [29]), as well as C. viatorum in cattle (Krumkamp et al., p. 111 in [29]). However, the role of animals in the transmission of $C$. hominis remains unclear, and the host range of C. viatorum is ill defined (Braima et al., p. 220 in [29]).

A study from the Czech Republic has shown that chickens infected as embryos with $C$. baileyi, a species that naturally infects chickens, or $C$. parvum, a species that is typically not infectious to chickens, could serve as a laboratory model for the propagation of Cryptosporidium isolates (Holubová et al., p. 180 in [29]).

\section{Human cryptosporidiosis and epidemiology}

In some countries, cryptosporidiosis diagnosis and surveillance is well established, but it was clear from presentations at IGCC-7 that even in most high-income countries, there is still a need to promote prompt diagnosis (Loury et al., p. 114 in [29]; Mravcová et al., p. 180 in [29]; Bahadur et al., p. 125 in [29]; TuA-P9 Malika; Costa et al., pp. 153, 210, 213 in [29]). Varying molecular epidemiology at national levels was revealed at IGCC-7 from species identifications (Chalmers et al., p. 104 in [29]; Kortbeek et al., p. 115 in [29]). Sequencing the gp60 gene was applied for surveillance and reported to be useful in outbreak investigations (Chalmers et al., p. 104 in [29]; Loury et al., p. 114 in [29]; Costa et al., pp. 110, 210 in [29]; Braima et al., p. 205 in [29]). This approach identified the introduction of novel subtypes by travellers. The development of bioinformatics tools for automatic genotyping of Cryptosporidium sequences was described (Yanta et al., p. 127 in [29]). Developments in multilocus genotyping (MLG) to improve discrimination over gp60 sequencing were described (Jellison et al., p. 122 in [29]) and validation of an MLG scheme was provided (Pérez-Cordón et al., p. 119 in [29]). Evidence for MSC6-7 as a marker for bovine-derived C. parvum was presented (Razakandrainibe et al., p. 168 in [29]). Several human epidemiological studies used whole-genome sequencing, and its value in discovering the genetic diversity of $C$. hominis in low-income settings was demonstrated (Ajjampur et al., p. 212 in [29]; Tichkule et al., p. 120 in [29]).

The lack of specific treatment options for human cryptosporidiosis means that prevention of infection is paramount. Understanding transmission and identifying key intervention points can be improved by genotyping to identify species and subtypes. Descriptive studies reported at IGCC-7 identified links between unusual human infections, and sometimes exposure to known or possible host sources, e.g. chipmunk genotype 1, gp60 XIVaA20G2T1, and squirrels (Beser et al., p. 206 in [29]), horse genotype and horses (Kopacz et al., p. 184 in [29]), and C. erinacei and hedgehogs (Costa et al., p. 210 in [29]). Wildlife sources of human infection need further investigation, but may present challenges to control. Household and neighborhood studies identified that, in some settings, zoonotic transmission is not as important as anthroponotic transmission, and that interventions for control should focus on sanitation and hygiene (Krumkamp et al., p. 111 in [29]; Eibach et al., p. 113 in [29]; Ajjampur et al., p. 212 in [29]). Such measures are 
important in schools where the potential for asymptomatic carriage was shown to increase the risk of infection in children (Köster et al., p. 208 in [29]; Muadica et al., p. 207 in [29]).

Clinical case reports are valuable, for example in identifying emergent, vulnerable patient groups, such as those being treated with biologics for rheumatoid arthritis (Kopacz et al., p. 184 in [29]). At IGCC-7, studies of long-term post-infection sequelae were presented, with cases reporting intestinal and extra-intestinal symptoms (Kortbeek et al., p. 117 in [29]; Carter et al., p. 116 in [29]). In a 12-month study, post-infection irritable bowel syndrome (IBS) or IBS-like symptoms were common, but there was no significant difference between C. parvum and C. hominis infection (Carter et al., p. 116 in [29]). It would be helpful in terms of patient management to advise patients of the likelihood of continued gastrointestinal symptoms for a prolonged period after a diagnosis of cryptosporidiosis. Further concern was raised from growing evidence of causal links between cryptosporidiosis and colon cancer, further highlighting the need for prevention and control (Certad et al., p. 101 in [29]).

\section{Genomes and genomic evolution Comparative genomics of Cryptosporidium spp.}

Comparative genomics has been an active area in Cryptosporidium research in recent years [19]. Several IGCC-7 presentations reported recent data on the genomics of several common Cryptosporidium spp. Recent developments in the comparative genomics of Cryptosporidium spp., including the initial sequencing of the genomes of $C$. parvum and $C$. hominis 15 years ago, have revealed high genetic similarity between the two species with a very different host range (Cacciò, p. 97 in [29], [1, 11, 25, 43]). Recent advances discussed the development of procedures for direct isolation of oocysts from clinical specimens for whole-genome sequencing $[2,14,16,36]$, and the wide use of NGS techniques for high-throughput acquisition of sequence data $[12,13,15,18,22,24,44]$. These methods have led to improved understanding of intra-species genetic variations in the major human-pathogenic species $C$. parvum and $C$. hominis [15, 16, 22, 24], the identification of speciesspecific genes [15, 24], elucidation of the role of genetic recombination in the generation of host-adapted $C$. parvum and virulent $C$. hominis variants [15, 17], and development of better molecular epidemiological tools [7, 9].

Two presentations focused on genome evolution within $C$. parvum and C. hominis. Identification of the genetic determinants of host adaptation among different gp60 subtype families of $C$. parvum using comparative genomics was discussed (Wang et al., p. 93 in [29]). Previously, the group reported whole-genome sequence differences between the bovineadapted IIa subtype family and the small ruminant-adapted IId subtype family [12]. The recent whole-genome sequence analysis of over $300 \mathrm{C}$. parvum isolates from various sources expanded the observation of significant differences in nucleotide sequences among $C$. parvum subtype families. The genetic differences between the IIa and IId subtype families appeared to be much smaller than those between the IIa and anthroponotic IIc subtype families. Most highly polymorphic genes among the three subtype families were subtelomeric genes encoding secretory proteins, especially the invasion-associated and immunodominant mucin proteins and members of the Cryptosporidium-specific SKSR gene family. These subtype families also differed in the copy numbers of subtelomeric genes encoding the MEDLE family of secretory proteins and insulinase-like proteases. These observations are in agreement with the genomic differences reported between IIa and IIc subtype families by two other research groups [24, 41].

The genomics of the dominant $C$. hominis subtype IbA10G2 in European countries was examined (Alako et al. p. 96 in [29]). This subtype accounts for $\sim 80 \%$ of human cases of $C$. hominis infections in this area, and is responsible for almost all outbreaks associated with $C$. hominis in Europe [8]. To understand the reasons for the prevalence of this subtype in Europe, these researchers sequenced the genomes of 19 IbA10G2 isolates from sporadic cases of cryptosporidiosis in the United Kingdom. This led to the generation of 7.4-13.8 million 150-bp, pairedend sequence reads per isolate, representing on average 112214-fold coverage of the Cryptosporidium genome. Variant analysis of the whole-genome sequence data has identified sequence conservation among isolates, with higher sequence polymorphism in the subtelomeric regions of chromosomes 1 , 2 , and 6 . This observation is similar to the findings reported recently by the Swedish group [34]. The authors concluded that there was clonal expansion of IbA10G2 in Europe. This is different from the population genetics of IbA10G2 in the United States, where genetic recombination is known to occur within the subtype due to the presence of other $C$. hominis subtypes within the country [15]. In Bangladesh, the high endemicity and subtype diversity of $C$. hominis has led to the extensive occurrence of genetic recombination within the species [13].

\section{Genomic insights into biology}

Three talks highlighted biological insights gleaned from genomic analysis. The analysis of 21 whole-genome sequences revealed that $C$. parvum splits into two subclades, one of which is anthroponotic and consists of subtypes IIc-a (Nader et al., p. 123 in [29]). This lineage also shares a subset of loci with $C$. hominis that are also undergoing convergent evolution driven by positive selection. The analysis revealed genetic exchange between Cryptosporidium subtypes and identification of recombinant regions that are enriched for positively selected genes and potential virulence factors, indicative of recent, adaptive introgression, likely within the last millennium. Finally, an analysis of 467 gp60 sequences revealed that the population structure of zoonotic and anthroponotic subtypes differed.

The genetic basis for virulence differences of various carcinogenic $C$. parvum isolates was examined (Audebert et al., p. 95 in [29]). The group has previously shown that the natural isolates of $C$. parvum named DID, TUM1 and $\mathrm{CHR}$ and all IIaA15G2R1 isolates are able to induce digestive adenocarcinoma in a rodent model, whereas $C$. parvum IOWA does not [6]. Whole-genome sequences of the three highly virulent carcinogenic $C$. parvum isolates were compared to the $C$. parvum IOWA II reference sequence. They found 126 common single-nucleotide variants in 91 coding sequences including several membranes and secreted proteins, as well as 
in previously characterized Cryptosporidium virulence factors implicated in sporozoite host cell invasion and intracellular multiplication/survival of the parasite. Their study has identified potential new virulence factors which will ideally be characterized using CRISPR/Cas9 technology [32].

Evidence has been found for developmental regulation of long noncoding RNAs (lncRNAs) and several other small ncRNAs in Cryptosporidium parvum (Li et al., p. 98, in [29]). This study utilized strand-specific RNA-Seq libraries of polyAand non-polyA-selected fractions from different developmental stages. The authors discovered that $\sim 20 \%$ of protein-coding genes are covered by transcription from the complementary strand, some of which are read through from neighboring genes. High-quality lncRNA candidates (>200 nt) revealed a subset with expression peaks $48 \mathrm{~h}$ post-infection. Some lncRNA candidates were conserved between Cryptosporidium species and even several Apicomplexa. Currently, their function is unknown. Further characterization of the Cryptosporidium non-coding transcriptome may provide further insights into parasite development and host-parasite interactions [23, 38, 39].

\section{Acquiring and utilizing genome sequences}

New technologies are also making Cryptosporidium genome sequences accessible and usable. The development of an Agilent SureSelect target enrichment approach [10] for whole-genome sequencing of Cryptosporidium directly from DNA isolated from stool samples, with the goal of developing high-resolution genetic markers for genotyping, and characterizing asymptomatic carriage and the potential for zoonotic transmission was presented (Khan et al., p. 99 in [29]). The approach utilizes 75,000 probes that cover $95 \%$ of the genome to perform target enrichment. The captured DNA is sequenced with Illumina. The authors showed that $30 \%$ of the genome sequence can be recovered when as little as $0.01 \mathrm{ng}$ of Cryptosporidium genomic DNA is present in the sample. When $5 \mathrm{ng}$ is present, $98 \%$ can be recovered. The probes, which were designed using $C$. parvum, can capture degenerate sequences; they are therefore able to detect species as distant as C. meleagridis, although with somewhat lower efficiency.

The availability of consistent, comparative and evidencebased genome assembly and annotation for the three closelyrelated species $C$. parvum, $C$. hominis, and $C$. tyzzeri was presented (Baptista et al., p. 151 in [29], [31]). Finally, new data and tools available in the free online resources CryptoDB.org have been reported on behalf of EuPathDB [3] by Warrenfeltz et al. p. 27 in [29]. Since IGCC-6, new data include the Baptista genome assemblies and annotation and several new RNA-Seq and SNP data sets. Sequence data from 14 species and strains are now available [40].

\section{Genetic manipulation}

Cryptosporidium can now be readily manipulated through CRISPR-driven recombination [37] and recent advances have simplified the required procedure. Remarkably, 50 base pairs are sufficient to serve as homology arms to drive sitespecific modification [27], allowing the use of simple PCR products as targeting vectors. Furthermore, a simplified infection protocol that delivers sporozoites by gavage (after buffering of the stomach) has replaced surgery-based delivery [33]. These modifications have streamlined reverse genetics for Cryptosporidium and the method has been adopted by numerous laboratories in the meantime. At this conference, research based on genetic manipulation of the parasite's sexual cycle, on the identification of a host-secreted family of proteins, and on the development of a mouse model of cryptosporidiosis to investigate host immunity was presented.

Genetic manipulation of $C$. parvum provided novel insights into the parasite's sexual cycle. Using a combination of fluorescent reporters and epitope-tagged transgenic parasite lines, it was shown that parasites rapidly undergo sexual differentiation in culture, leading to the formation of male and female gametes (Striepen, p. 54 in [29], [35]). Male gametes were clearly identified by the expression of a Cryptosporidium hapless2 homolog (HAP2, cgd8_2220), and cell oocyst wall protein 1 (COWP1, cgd6_2090) proved to be a reliable marker of female gametes. Using a $C$. parvum transgenic strain that expresses the fluorescent protein tdTomato driven by the COWP1 female specific promoter, female gametes were isolated by fluorescence-activated cell sorting from both cell culture and from actively infected $\mathrm{IFN}_{\gamma}^{-/-}$mice. Comparative analysis of gene expression by RNA sequencing showed that female gametes from cell culture and infected mice have very similar expression profiles, with upregulation of genes required for meiosis, wall formation, and oocyst persistence. However, female gametes from infected mice demonstrated an RNA expression profile that more closely aligned with the expression profile of sporozoites, suggesting that fertilization (and hence the production of new sporozoites) occurred in vivo but not in vitro. Follow-up experiments using a CRE recombinase-based assay to detect gamete fusion supported this hypothesis. Within mice, fusion, and fertilization were readily detectable by microscopy. However, in cell culture, no fusion or fertilization could be detected. This lack of fusion results in a lack of new oocyst production and, ultimately, a block of continuous parasite growth in cell culture (Striepen, p. 54 in [29]).

Secretory proteins delivered to the infected cell play important roles as effector molecules and are used by many pathogens to manipulate their hosts. Rapid coevolution of host and parasite drives high levels of polymorphism in the genes that encode these effectors. Using a bioinformatics approach, candidate host-secreted proteins were identified in C. parvum and subsequently tested by epitope tagging at their genetic loci using CRISPR-driven recombination. From this cohort of candidates, one protein localized to the cytoplasm of infected cells in both cell culture and in the intestinal epithelial cells of infected $\mathrm{IFN}_{\gamma}^{-/-}$mice. This protein was not visible in sporozoites by immunofluorescent microscopy but could be easily detected in infected host cells, suggesting a delivery system following parasite invasion. Treatment of infected cells with Brefeldin A ablated export, suggesting that this protein passes through the canonical secretory pathway of the parasite to reach the host cell, traveling from the ER to the Golgi. The emerging model for effector export in Cryptosporidium identifies a specific amino acid sequence that distinguishes proteins destined for the host cell (Striepen, p. 54 in [29]). 
Finally, the tools of genetic manipulation were also shown to extend to $C$. tyzzeri, a species that produces natural infection in wild and laboratory mice (Striepen, p. 54 in [29], [31]). A new isolate of $C$. tyzzeri was isolated in the United States (Athens, Georgia), and the genome was sequenced, assembled de novo, and fully annotated. Complete genomic alignment confirmed that $C$. tyzzeri is indeed closely related to the human infectious species, C. parvum and C. hominis, with 95-96\% identity at the nucleotide level. Using a draft of the parasite genome, and CRISPR-driven homologous repair, a stable transgenic $C$. tyzzeri strain was created expressing both fluorescent and luminescent reporters. With this transgenic parasite line, it was shown that healthy adult mice develop a robust infection that is self-limiting, with intestinal pathology that mirrors human cryptosporidiosis. Following initial exposure to $C$. tyzzeri, mice then developed a marked resistance to subsequent infections. Further, this resistance could be replicated through immunization with gamma-irradiation attenuated parasites. Control of infection and the resistance to subsequent infections was shown to be both IFN $\gamma$ and T-cell-dependent, again mirroring what is seen in human cryptosporidiosis. This natural murine model of cryptosporidiosis is anticipated to develop into an inexpensive platform for both vaccine development and drug testing (Striepen, p. 54 in [29]).

\section{Host-parasite interaction (immunology, microbiome)}

Investigating host-parasite interactions to better understand parasitic infection and survival within the host is a prerequisite to develop strategies for prevention and treatment of infectious diseases. Recent advances in the genetic manipulation of Cryptosporidium combined with new in vitro and in vivo models will allow a better understanding of these interactions.

It is now well known that Toxoplasma gondii organelles such as rhoptries or dense granules store many effector proteins targeting host signaling and transcription [17]. It was also clearly demonstrated that $C$. parvum also exports proteins into the cytoplasm of the epithelial host cell (Dumaine et al., p. 100 in [29]. MEDLE2, a gene that belongs to a polymorphic gene family, is produced during the course of the infection soon after the parasite makes contact with the intestinal epithelial cell and is exported to the cytoplasm. This process occurs at all stages of the parasite (asexual and sexual stages) and requires the presence of a signal peptide and specific sequence information that directs the export of the MEDLE2 protein into the host cell. Although the precise function of this protein is not yet known, genes in the unfolded protein response pathway are upregulated in cells that express MEDLE2. Dumaine's elegant study paves the way for the characterization of $C$. parvum virulence factors that modulate host metabolism to the parasite's benefit, or help the pathogen escape from the immune response (Dumaine et al., p. 100 in [29]).

The range of tools to investigate the immune response to C. parvum infection and the host-pathogen interaction has expanded. For some investigations, mouse models can present limitations. For example, in contrast to neonatal mice, adult mice are resistant to $C$. parvum infection and there was thus no suitable immunocompetent adult mouse model to study Cryptosporidium infection. To fill this gap, Sateriale et al. isolated a line of Cryptosporidium tyzzeri, a species that naturally colonizes the small intestine of mice and is also genetically tractable with CRISPR/Cas9 (Sateriale et al., p. 46 in [29], [31]). With this new model and several transgenic mouse lines, it was possible to confirm in adult mice that interferon $\gamma$ acts as a key cytokine and that $\mathrm{T}$ cells are important for the resolution of the infection. More importantly, this study demonstrated that primary infection protects against a homologous challenge, reviving interest in developing a vaccine to prevent or limit the severity of cryptosporidiosis. Major improvements in the ability to follow the progression of the Cryptosporidium life cycle were presented. This was accomplished by generating several transgenic lines expressing a reporter controlled by stage-specific promoters, such as promoters active during sexual differentiation and oocyst formation. This work also highlighted the limitation of the classical in vitro culture methods using epithelial cell lines. Evidence was presented that male gametes are able to find macrogamonts but do not fertilize them efficiently. In this context, although not presented at the meeting, readers may be interested in the recent publication by Wilke et al. [42] who describe an air-liquid-interface cultivation system that supports life-cycle completion and de novo production of oocysts that can infect mice. This research constitutes a breakthrough to investigate genetic crosses in vitro. It is also a valuable tool for studying host-parasite interactions and to maintain stable Cryptosporidium strains. The precise mechanism by which $C$. parvum adheres to the surface of epithelial cells and successfully invades the host cell is still unknown. Three TSP1 domains containing proteins (TSP3, TSP4, and TSP7) localized on the surface of sporozoites and merozoites that bind to HCT8 cells in a dose-dependent manner were identified (Yin et al., p 35 in [29]). Further investigations suggest that these proteins could bind to heparan sulfate on host cells.

Our knowledge of the immune response to cryptosporidiosis is constantly improving. This research is of major importance to develop targeted immunostimulation strategies and vaccines. An overview on how innate responses shape Cryptosporidium infection with a particular focus on the role of mononuclear phagocytes was presented (Laurent et al., p. 38 in [29]) [20]. Previous findings highlighted the key role of dendritic cells in the control of the acute phase of the infection. Further investigations with transgenic mice revealed that a specific subset of dendritic cells, called $\mathrm{cDC} 1$, that express the transcription factor Batf3, plays a major role in the control of the acute phase of the infection, but also in the definitive clearance of the parasite [28]. These cells have the ability to produce large amounts of IL-12 during the course of infection but also interferon $\gamma$ that might activate larger local producers of interferon $\gamma$, such as ILC1 and TH1 cells, for efficient control of Cryptosporidium development in epithelial cells. However, not all mononuclear phagocytes are involved in protection and it was shown that inflammatory monocytes (Ly6c+) play no role in protection, but participate in the loss of intestinal permeability by producing large amounts of IL1 $\beta$ in close contact with infected epithelial cells. This process was shown to destabilize cellular junctions. Paneth cells (PCs), specialized epithelial cells that produce antimicrobial peptides at the base 
of the intestinal crypt, are known to be active against free C. parvum stages (Lacroix-Lamandé et al., p. 33 in [29]). Neonatal mice deficient for PCs presented higher levels of infection, and the number of granule-positive PCs and lysozyme-positive PCs in infected conventional mice decreased, thus supporting the view that antimicrobial peptides including lysozymes participate in the efficiency of the innate immune response. As an escape mechanism, C. parvum can limit some of these effectors, such as CRAMP, an antimicrobial peptide specifically expressed in the neonatal intestine.

Enteric infections in early life can alter the development of the intestinal immune response and the establishment of the intestinal microbiota. This process can have long-term consequences on gut health. Epidemiological studies have reported that after resolution of $C$. parvum infection, patients still suffer from abdominal pain. Long after recovery, mice presented an alteration of immune cell composition and microbiota associated with increased visceral susceptibility (Lacroix-Lamandé et al., p. 34 in [29]). In addition, mice infected with C. parvum at a young age were more susceptible to Salmonella infection as adults, thus highlighting the detrimental role of early cryptosporidiosis on long-term gut health and susceptibility to enteric diseases. In addition, there is accumulating evidence that C. parvum infection could be associated with the development of digestive neoplasia. In a corticoid dexamethasone-treated adult severe combined immunodeficient (SCID) mouse model, cryptosporidiosis is associated with the presence of digestive adenocarcinoma (Certad et al., p. 101 in [29]). Neoplastic lesions were repeated with a 3D culture model from the adult murine colon maintained ex vivo for a month. This original model allowed the researchers to emphasize the pivotal role of the Wnt pathway together with the alteration of the cytoskeleton [5].

Research on host-parasite interaction has typically been the realm of immunologists. Particularly with respect to enteric pathogens, this view is changing, as is the definition of host. The improved understanding of the many functions of the abundant microbial population living in the gastro-intestinal tract, as well as other organs, has expanded the definition of host to a multi-species consortium. In terms of number of cells and metabolic function diversity, this multi-species consortium has been shown to be dominated by commensal bacteria. Consistent with this changing perception of the host, a field of research focused on understanding the interaction of the intestinal microbiome with enteric protozoa, like Cryptosporidium, Giardia, and Entamoeba is emerging. Cryptosporidium parvum infection in neonatal mice induced lasting dysbiosis (Lacroix-Lamandé et al., p. 33 in [29]). Research on the interaction between the intestinal microbiome and Cryptosporidium conducted in Giovanni Widmer's laboratory at Tufts University was the focus of two talks. The interaction between the intestinal microbiome in mice and the proliferation of $C$. parvum and $C$. tyzzeri was investigated (Widmer et al., p. 92 in [29]; Oliveira et al., p. 45 in [29]). By enumerating the output of oocysts in the feces, the authors explored the effect of nutritional interventions on the severity of cryptosporidiosis. Probiotics, prebiotics, and dietary fiber can affect the severity of the infection, albeit in different ways. Mice fed prebiotics or dietary fiber developed a less severe infection than control mice fed no prebiotics or diet lacking fiber, respectively. In contrast, probiotics containing live Lactobacillus, Bifidobacterium, and Streptococcus bacteria were shown to have a opposite effect. Mice receiving this dietary supplement excreted significantly more oocysts over the course of the infection. $16 \mathrm{~S}$ amplicon sequencing was used to investigate the effect of the dietary treatment on the intestinal microbiome and to identify bacterial taxa which correlate in abundance with parasite proliferation. Given the lack of effective drugs to control cryptosporidiosis, nutritional interventions could play a beneficial role in mitigating the effect of cryptosporidiosis, particularly in infants living in low-income countries where cryptosporidiosis is highly prevalent $[25,26]$.

\section{Diagnosis and treatment}

During human diarrhea outbreaks, countries such as France prioritize the search for bacterial or viral agents, and a parasitological examination of stools is only carried out with a long delay, making the availability of samples very random. In order to have a simple test allowing a posteriori diagnosis of cryptosporidiosis, a simple test based on the search for antibodies in the saliva of patients was developed and then evaluated (Elwin et al., p. 196 in [29]). They showed that the results obtained with these saliva samples are correlated with those obtained by testing for antibodies in the serum, and that antibody levels peak 60 days after contamination and then disappear in the months that follow. Regarding the coprological diagnosis, a large number of recently marketed multiplex tests have been evaluated, and their performance found to be satisfactory with regard to the detection of Cryptosporidium (Basmaciyan et al., p. 231 in [29]; Lamien Meda et al., p. 195 in [29]; Costa et al., p. 200 in [29]; Razakandrainibe et al., p. 201 in [29], [4]).

Cryptosporidiosis is a leading cause of diarrheal disease. There remains a critical need for new approaches to the treatment of this infection. There are no vaccines and nitazoxanide (NTZ) is the only drug approved for the treatment of cryptosporidiosis. Basic research to drive new molecule development has stagnated mainly because of the lack of genetic tools and suitable animal models. The pace of progress in these areas is expected to increase in the next decade, especially fueled by the completion of several Cryptosporidium genome sequences and the new-found ability to genetically engineer Cryptosporidium, making it possible to non-invasively track parasite tissue burden throughout the gastrointestinal tract (Gargala p. 234 in [29]). As there is no continuous culture for Cryptosporidium, investigators have relied on short-term maintenance in cultured cell monolayers to assess the efficacy of drugs. Oligoarginine synthetically attached to NTZ (NTZ$\mathrm{CPP}$ ) induced a drastic improvement of drug activity as compared to NTZ. These results are highly attractive and represent an encouraging step toward developing an alternative therapy to NTZ (Nguyen et al., p. 190 in [29]). The routes of drug uptake are still poorly known and it is unclear whether, for intestinal cryptosporidiosis, the optimal anticryptosporidial agent should be absorbed systemically and/or retained in the gastrointestinal tract. Ideally, the treatment of extra-digestive or severe cryptosporidiosis calls for an injectable compound. Aminoxanide, 
a new amino-ester thiazolide derivative and the first soluble form of NTZ was identified as a candidate (Diawara et al., p. 238 in [29]). Developing therapeutics to reduce morbidity and mortality due to Cryptosporidium spp. among children in low-resource settings is a challenge (De Hostos et al., p. 237, in [29]), and a study has been conducted aiming to explore the traditional Ivorian pharmacopoeia to identify new effective compounds against $C$. parvum. In this context, an ethnobotanical survey focussing on anti-diarrheal therapeutic habits led to the evaluation of the anticryptosporidial effect of plant extracts and found that 6 out of 28 extracts showed greater efficacy than paromomycin (Tuo et al., p. 192 in [29]).

\section{References}

1. Abrahamsen MS, Templeton TJ, Enomoto S, Abrahante JE, Zhu G, Lancto CA, Deng M, Liu C, Widmer G, Tzipori S, Buck GA, Xu P, Bankier AT, Dear PH, Konfortov BA, Spriggs HF, Iyer L, Anantharaman V, Aravind L, Kapur V. 2004. Complete genome sequence of the apicomplexan, Cryptosporidium parvum. Science, 304, 441-445.

2. Andersson S, Sikora P, Karlberg ML, Winiecka-Krusnell J, Alm E, Beser J, Arrighi RB. 2015. It's a dirty job - a robust method for the purification and de novo genome assembly of Cryptosporidium from clinical material. Journal of Microbiological Methods, 113, 10-12.

3. Aurrecoechea C, Barreto A, Basenko EY, Brestelli J, Brunk BP, Cade S, Crouch K, Doherty R, Falke D, Fischer S, Gajria B, Harb OS, Heiges M, Hertz-Fowler C, Hu S, Iodice J, Kissinger JC, Lawrence C, Li W, Pinney DF, Pulman JA, Roos DS, Shanmugasundram A, Silva-Franco F, Steinbiss S, Stoeckert CJ Jr, Spruill D, Wang H, Warrenfeltz S, Zheng J. 2017. EuPathDB: the eukaryotic pathogen genomics database resource. Nucleic Acids Research, 45, D581-D591.

4. Autier B, Belaz S, Razakandrainibe R, Gangneux JP, RobertGangneux F. 2018. Comparison of three commercial multiplex PCR assays for the diagnosis of intestinal protozoa. Parasite, 25, 48.

5. Baydoun M, Vanneste SB, Creusy C, Guyot K, Gantois N, Chabe M, Delaire B, Mouray A, Baydoun A, Forzy G, Chieux V, Gosset P, Senez V, Viscogliosi E, Follet J, Certad G. 2017. Three-dimensional (3D) culture of adult murine colon as an in vitro model of cryptosporidiosis: proof of concept. Scientific Reports, 7, 17288.

6. Benamrouz S, Conseil V, Chabe M, Praet M, Audebert C, Blervaque R, Guyot K, Gazzola S, Mouray A, Chassat T, Delaire B, Goetinck N, Gantois N, Osman M, Slomianny C, Dehennaut V, Lefebvre T, Viscogliosi E, Cuvelier C, Dei-Cas E, Creusy C, Certad G. 2014. Cryptosporidium parvum-induced ileo-caecal adenocarcinoma and Wnt signaling in a mouse model. Disease Models and Mechanisms, 7, 693-700.

7. Beser J, Hallstrom BM, Advani A, Andersson S, Ostlund G, Winiecka-Krusnell J, Lebbad M, Alm E, Troell K, Arrighi RBG. 2017. Improving the genotyping resolution of Cryptosporidium hominis subtype IbA10G2 using one step PCRbased amplicon sequencing. Infection Genetics and Evolution, 55, 297-304.

8. Cacciò SM, Chalmers RM. 2016. Human cryptosporidiosis in Europe. Clinical Microbiology and Infection, 22(6), 471-480.

9. Chalmers RM, Perez-Cordon G, Caccio SM, Klotz C, Robertson LJ, Participants of the Cryptosporidium Genotyping w. 2018. Cryptosporidium genotyping in Europe: the current status and processes for a harmonised multi-locus genotyping scheme. Experimental Parasitology, 191, 25-30.

10. Chung J, Son DS, Jeon HJ, Kim KM, Park G, Ryu GH, Park WY, Park D. 2016. The minimal amount of starting DNA for Agilent's hybrid capture-based targeted massively parallel sequencing. Scientific Reports, 6, 26732.

11. Efstratiou A, Ongerth JE, Karanis P. 2017. Waterborne transmission of protozoan parasites: review of worldwide outbreaks - an update 2011-2016. Water Research, 114, 14-22.

12. Feng Y, Li N, Roellig DM, Kelley A, Liu G, Amer S, Tang K, Zhang L, Xiao L. 2017. Comparative genomic analysis of the IId subtype family of Cryptosporidium parvum. International Journal for Parasitology, 47, 281-290.

13. Gilchrist CA, Cotton JA, Burkey C, Arju T, Gilmartin A, Lin Y, Ahmed E, Steiner K, Alam M, Ahmed S, Robinson G, Zaman SU, Kabir M, Sanders M, Chalmers RM, Ahmed T, Ma JZ, Haque R, Faruque ASG, Berriman M, Petri WA. 2018. Genetic diversity of Cryptosporidium hominis in a Bangladeshi community as revealed by whole-genome sequencing. Journal of Infection Diseases, 218, 259-264.

14. Guo Y, Li N, Lysen C, Frace M, Tang K, Sammons S, Roellig DM, Feng Y, Xiao L. 2015. Isolation and enrichment of Cryptosporidium DNA and verification of DNA purity for whole-genome sequencing. Journal of Clinical Microbiology, 53, 641-647.

15. Guo Y, Tang K, Rowe LA, Li N, Roellig DM, Knipe K, Frace M, Yang C, Feng Y, Xiao L. 2015. Comparative genomic analysis reveals occurrence of genetic recombination in virulent Cryptosporidium hominis subtypes and telomeric gene duplications in Cryptosporidium parvum. BMC Genomics, 16,320 .

16. Hadfield SJ, Pachebat JA, Swain MT, Robinson G, Cameron SJ, Alexander J, Hegarty MJ, Elwin K, Chalmers RM. 2015. Generation of whole genome sequences of new Cryptosporidium hominis and Cryptosporidium parvum isolates directly from stool samples. BMC Genomics, 16, 650.

17. Hakimi M-A, Olias P, Sibley LD. 2017. Toxoplasma effectors targeting host signaling and transcription. Clinical Microbiology Reviews, 30, 615-645.

18. Ifeonu OO, Chibucos MC, Orvis J, Su Q, Elwin K, Guo F, Zhang H, Xiao L, Sun M, Chalmers RM, Fraser CM, Zhu G, Kissinger JC, Widmer G, Silva JC. 2016. Annotated draft genome sequences of three species of Cryptosporidium: Cryptosporidium meleagridis isolate UKMEL1, C. baileyi isolate TAMU-09Q1 and C. hominis isolates TU502_2012 and UKH1. Pathogens and Disease, 74, ftw080.

19. Khan A, Shaik JS, Grigg ME. 2018. Genomics and molecular epidemiology of Cryptosporidium species. Acta Tropica, 184, $1-14$.

20. Laurent F, Lacroix-Lamandé S. 2017. Innate immune responses play a key role in controlling infection of the intestinal epithelium by Cryptosporidium. International Journal for Parasitology, 47, 711-721.

21. Li J, Shi K, Sun F, Li T, Wang R, Zhang S, Jian F, Ning C, Zhang L. 2019. Identification of human pathogenic Enterocytozoon bieneusi, Cyclospora cayetanensis, and Cryptosporidium parvum on the surfaces of vegetables and fruits in Henan, China. International Journal of Food Microbiology, 307, 108292.

22. Liu S, Roellig DM, Guo Y, Li N, Frace MA, Tang K, Zhang L, Feng Y, Xiao L. 2016. Evolution of mitosome metabolism and invasion-related proteins in Cryptosporidium. BMC Genomics, $17,1006$.

23. Ming Z, Gong AY, Wang Y, Zhang XT, Li M, Li Y, Pang J, Dong S, Strauss-Soukup JK, Chen XM. 2018. Trans-suppression of host CDH3 and LOXL4 genes during Cryptosporidium 
parvum infection involves nuclear delivery of parasite Cdg7_FLc_1000 RNA. International Journal for Parasitology, 48, 423-431.

24. Nader JL, Mathers TC, Ward BJ, Pachebat JA, Swain MT, Robinson G, Chalmers RM, Hunter PR, van Oosterhout C, Tyler KM. 2019. Evolutionary genomics of anthroponosis in Cryptosporidium. Nature Microbiology, 4, 826-836.

25. Oliveira BCM, Widmer G. 2018. Probiotic product enhances susceptibility of mice to cryptosporidiosis. Applied and Environmental Microbiology, 84, e01408-e01418.

26. Oliveira BCM, Bresciani KDS, Widmer G. 2019. Deprivation of dietary fiber enhances susceptibility of mice to cryptosporidiosis. PLoS Neglected Tropical Disease. 13, e0007411.

27. Pawlowic MC, Somepalli M, Sateriale A, Herbert GT, Gibson AR, Cuny GD, Hedstrom L, Striepen B. 2019. Genetic ablation of purine salvage in Cryptosporidium parvum reveals nucleotide uptake from the host cell. Proceedings of the National Academy of Sciences of the United States of America, 116, 21160-21165.

28. Potiron L, Lacroix-Lamandé S, Marquis M, Levern Y, Fort G, Franceschini I, Laurent F. 2019. Batf3-Dependent intestinal dendritic cells play a critical role in the control of Cryptosporidium parvum Infection. Journal of Infection Diseases, 219, 925-935.

29. Program of the 7th International Giardia and Cryptosporidium Conference. https://en.rouentourisme.com/wp-content/uploads// 2019/06/Programme-définitif-modifié-200619.pdf and https:// hal-normandie-univ.archives-ouvertes.fr/hal-02495405.

30. Ryan U, Hijjawi N, Xiao L. 2018. Foodborne cryptosporidiosis. International Journal for Parasitology, 48, 1-12.

31. Sateriale A, Slapeta J, Baptista R, Engiles JB, Gullicksrud JA, Herbert GT, Brooks CF, Kugler EM, Kissinger JC, Hunter CA, Striepen B. 2019. A genetically tractable, natural mouse model of cryptosporidiosis offers insights into host protective immunity. Cell Host and Microbe, 26(135-146), e5.

32. Sateriale A, Pawlowic M, Vinayak S, Brooks C, Striepen B. 2020. Genetic manipulation of Cryptosporidium parvum with CRISPR/Cas9. Methods in Molecular Biology, 2052, 219-228.

33. Sateriale A, Pawlowic M, Vinayak S, Brooks C, Striepen B. 2020. Genetic manipulation of Cryptosporidium parvum with CRISPR/Cas9, in Cryptosporidium, Mead J, Arrowood M, Editors. Methods in Molecular Biology, Vol. 2052. Humana: New York, NY.

34. Sikora P, Andersson S, Winiecka-Krusnell J, Hallstrom B, Alsmark C, Troell K, Beser J, Arrighi RB. 2017. Genomic variation in IbA10G2 and other patient-derived Cryptosporidium hominis subtypes. Journal of Clinical Microbiology, 55, 844-858.
35. Tandel J, English ED, Sateriale A, Gullicksrud JA, Beiting DP, Sullivan MC, Pinkston B, Striepen B. 2019. Life cycle progression and sexual development of the apicomplexan parasite Cryptosporidium parvum. Nature Microbiology, 4, 2226-2236.

36. Troell K, Hallstrom B, Divne AM, Alsmark C, Arrighi R, Huss M, Beser J, Bertilsson S. 2016. Cryptosporidium as a testbed for single cell genome characterization of unicellular eukaryotes. BMC Genomics, 17, 471.

37. Vinayak S, Pawlowic MC, Sateriale A, Brooks CF, Studstill CJ, Bar-Peled Y, Cipriano MJ, Striepen B. 2015. Genetic modification of the diarrhoeal pathogen Cryptosporidium parvum. Nature, 523, 477-480.

38. Wang Y, Gong AY, Ma S, Chen X, Li Y, Su CJ, Norall D, Chen J, Strauss-Soukup JK, Chen XM. 2017. Delivery of Parasite RNA transcripts into infected epithelial cells during Cryptosporidium infection and its potential impact on host gene transcription. Journal of Infection Diseases, 215, 636-643.

39. Wang Y, Gong AY, Ma S, Chen X, Strauss-Soukup JK, Chen XM. 2017. Delivery of parasite Cdg7_Flc_0990 RNA transcript into intestinal epithelial cells during Cryptosporidium parvum infection suppresses host cell gene transcription through epigenetic mechanisms. Cellular Microbiology, 19 (11), e12760.

40. Warrenfeltz S, Kissinger JC, EuPath DBT. 2020. Accessing Cryptosporidium omic and isolate data via CryptoDB.org. Methods in Molecular Biology, 2052, 139-192.

41. Widmer G, Lee Y, Hunt P, Martinelli A, Tolkoff M, Bodi K. 2012. Comparative genome analysis of two Cryptosporidium parvum isolates with different host range. Infection Genetics and Evolution, 12, 1213-1221.

42. Wilke G, Funkhouser-Jones LJ, Wang Y, Ravindran S, Wang Q, Beatty WL, Baldridge MT, VanDussen KL, Shen B, Kuhlenschmidt MS, Kuhlenschmidt TB, Witola WH, Stappenbeck TS, Sibley LD. 2019. A stem-cell-derived platform enables complete Cryptosporidium development in vitro and genetic tractability. Cell Host and Microbe, 26, 123-134.

43. Xu P, Widmer G, Wang Y, Ozaki LS, Alves JM, Serrano MG, Puiu D, Manque P, Akiyoshi D, Mackey AJ, Pearson WR, Dear $\mathrm{PH}$, Bankier AT, Peterson DL, Abrahamsen MS, Kapur V, Tzipori S, Buck GA. 2004. The genome of Cryptosporidium hominis. Nature, 431, 1107-1112.

44. Xu Z, Guo Y, Roellig DM, Feng Y, Xiao L. 2019. Comparative analysis reveals conservation in genome organization among intestinal Cryptosporidium species and sequence divergence in potential secreted pathogenesis determinants among major human-infecting species. BMC Genomics, 20, 406.

Cite this article as: Widmer G, Carmena D, Kváč M, Chalmers RM, Kissinger JC, Xiao L, Sateriale A, Striepen B, Laurent F, LacroixLamandé S, Gargala G \& Favennec L. 2020. Update on Cryptosporidium spp.: highlights from the Seventh International Giardia and Cryptosporidium Conference. Parasite 27, 14. 
Reviews, articles and short notes may be submitted. Fields include, but are not limited to: general, medical and veterinary parasitology; morphology, including ultrastructure; parasite systematics, including entomology, acarology, helminthology and protistology, and molecular analyses; molecular biology and biochemistry; immunology of parasitic diseases; host-parasite relationships; ecology and life history of parasites; epidemiology; therapeutics; new diagnostic tools.

All papers in Parasite are published in English. Manuscripts should have a broad interest and must not have been published or submitted elsewhere. No limit is imposed on the length of manuscripts.

Parasite (open-access) continues Parasite (print and online editions, 1994-2012) and Annales de Parasitologie Humaine et Comparée (1923-1993) and is the official journal of the Société Française de Parasitologie. 